\title{
The role of iron in pulmonary pathology
}

\author{
Heena Khiroya ${ }^{1,2^{*}}$ and Alice M. Turner ${ }^{1,3}$
}

\begin{abstract}
Respiratory disease accounts for a large proportion of emergency admissions to hospital and diseaseassociated mortality. Genetic association studies demonstrate a link between iron metabolism and pulmonary disease phenotypes. IREB2 is a gene that produces iron regulatory protein 2 (IRP2), which has a key role in iron homeostasis. This review addresses pathways involved in iron metabolism, particularly focusing on the role of IREB2. In addition to this, environmental factors also influence phenotypic variation in respiratory disease, for example inhaled iron from cigarette smoke is deposited in the lung and causes tissue damage by altering iron homeostasis. The effects of cigarette smoke are detailed in this article, particularly in relation to lung conditions that favour the upper lobes, such as emphysema and lung cancer. Clinical applications of iron homeostasis are also discussed in this review, especially looking at the pathophysiology of chronic obstructive pulmonary disease, lung cancer, pulmonary infections and acute respiratory distress syndrome. Promising new treatments involving iron are also covered.
\end{abstract}

Keywords: ARDS, Cancer, Cigarette, COPD, Infection, IREB2, Iron

\section{Introduction}

Environmental risk factors, such as smoking status and air pollution, interact with genes, in order to produce pathology. The variation of phenotypes seen in patients with the same diagnosis can be vast, even if they have been exposed to the same environmental factors. These differences in chronic disease manifestations point towards a clear genetic component. Understanding the interaction between the environment and genetics can theoretically allow us to predict susceptibility towards certain diseases and target treatments. Respiratory disease is a great socioeconomic burden on the UK's health services, with it accounting for 1 in 5 deaths, and being the second most common cause of emergency admissions [1]. It is therefore important to understand what drives pulmonary pathology.

The lungs are continually exposed to metals in the atmosphere. Iron is in great abundance in the earth's core [2] and from here is able to dissolute into the atmosphere. Inhalational iron therefore may be a source of environmental variation within respiratory disease. Iron is also found in cigarette smoke, the environmental factor with the strongest causative link to pulmonary pathology. Through

\footnotetext{
* Correspondence: h.khiroya@bham.ac.uk

${ }^{1}$ School of Clinical and Experimental Medicine, University of Birmingham, Birmingham B15 2TT, UK

${ }^{2}$ Centre for Translational Inflammation Research, Queen Elizabeth Hospital, Mindelsohn Way, Edgbaston, Birmingham B15 2GW, UK

Full list of author information is available at the end of the article
}

cigarette smoking, iron has been shown to alter disrupt homeostasis in the lung, making the tissue more susceptible to damage [3]. Iron concentrations in lung cell lines and bronchoalveolar lavage (BAL) fluid have been studied, and are increased in cases of disease [4].

Alterations in iron homeostasis have also been examined from a genetic viewpoint. Iron responsive element binding protein 2 (IREB2) is a gene on chromosome 15 , and its protein product is iron regulatory protein 2 (IRP2): a key player in maintaining iron balance. IREB2 is in strong linkage disequilibrium (LD) with nicotine receptor genes (CHRNA3 and 5) [5] and it is this that led IREB2 to be investigated in relation to respiratory conditions such as chronic obstructive pulmonary disease and lung cancer. Interest in iron came later as a result of IREB2 genetic association studies to establish links between iron and pulmonary phenotypes. This article reviews the role of iron metabolism and iron homeostasis in lung disease, particularly focusing on IREB2.

\section{Review \\ Cellular iron balance}

Iron is most commonly found in ferric $\left(\mathrm{Fe}^{3+}\right)$ and ferrous $\left(\mathrm{Fe}^{2+}\right)$ states; the more stable of these under normoxic conditions is $\mathrm{Fe}^{3+} . \mathrm{Fe}^{2+}$ reduces oxygen to form superoxide radicals [6] which cause damage to cells and ultimately result in apoptosis [7]. To reduce the toxicity of free iron, homeostatic mechanisms are in place to ensure appropriate 
systemic and intracellular iron conditions. Iron is stored in hepatocytes, and macrophages in the liver and spleen. These levels remain constant in spite of fluctuations in the diet. The main regulator of systemic iron control is hepcidin [8], a hormone produced in the liver. Dietary iron is absorbed across the duodenal mucosa; modulation of this is controlled by signals from the liver $[8,9]$. Increasing levels of iron in the plasma induce HAMP, a protein that encodes hepcidin production. Hepcidin then reduces the amount of iron moving from stores into the plasma as well as the amount absorbed from the diet. Conversely, when plasma levels of iron are low, hepcidin production is downregulated in order to increase the amount of iron that can be moved from hepatocytes and macrophages, as well as absorption from dietary sources [10].

There is a separate second system that regulates iron homeostasis within cells. In the bloodstream, iron binds to transferrin [11]. Transferrin receptor 1 is expressed on the cell membrane, and most cells can regulate the influx of iron via this channel [12]. Figure 1 demonstrates the transferrin-to-cell cycle in more detail. Non-tranferrin bound iron species are found in the plasma, the main form is thought to be $\mathrm{Fe}^{3+}$ bound to citrate [13]. Mechanisms surrounding cellular uptake are unknown but thought to be independent of endocytosis [13]. Iron regulatory proteins 1 and 2 (IRP1 and IRP2) register iron concentrations in the cytosol [14] and post-transcriptionally regulate expression of transferrin receptors and iron metabolism genes to optimise cellular iron availability [15]. Macrophages provide an additional route for iron concentrations to be maintained intracellularly via phagoytosis of damaged erythrocytes [10]. The phagocytosed iron is either stored as ferritin in the cytoplasm and is subject to regulation by the IRPs, or travels through ferroportin to the extracellular fluid [10].

Genetic ablation studies in mice have shown that IRP2 has a key role in mammalian iron metabolism [16, 17]. In contrast, the absence of IRP1 has little effect on iron homeostasis because IRP2 is able to increase its activity in a compensatory fashion [18]. Under conditions of iron starvation, IRPs bind to specific RNA stem-loop structures called iron responsive elements (IREs) to stabilise the transferrin receptor and inhibit the translation of ferritin mRNA [15]. Iron dissociates from transferrin, and ferritin biosynthesis is prevented, therefore iron is not stored and able to be metabolised [19]. When cells are abundant with iron; sulphur clusters with iron at the core of IRP1 [15], whereas IRP2 undergoes proteosomal degradation [20]. The result of both these actions is inactivation of the IRPs, which causes transferrin receptor 1 mRNA degradation and ferritin mRNA translation. This ensures less iron is taken into cells via transferrin receptor 1 , and free iron is stored in the form of ferritin [19].
Unlike IRP1, IRP2 remains stable under hypoxic conditions and is highly active with regards to binding IREs [15]. Hypoxia-inducible factors activate the IRP genes to increase the amounts of iron available for erythropoiesis [21]. Hypoxia appears to increase IRP2 levels by a posttranslational mechanism involving protein stability [22]. Ischaemia-reperfusion injury of the lung following prolonged hypoxia shows elevated levels of iron [23], which is important to note, as both type 1 and type 2 respiratory failure are characterised by hypoxia.

\section{The effects of cigarette smoke}

Particulate matter (including iron) from cigarette smoke is deposited in the lungs and can cause damage by altering iron homeostasis. Lung cells are different from other cell lines in that they are continually exposed to changes in oxygen levels, which also have effects on iron homeostasis. A study done in rats showed that airway iron was elevated after exposure to cigarette smoke, which led to increased oxidative stress and release of IL-8 [3]. Generation of oxidative stress and cytokine accumulation contribute to tissue damage by the process of neutrophil recruitment [24].

Conditions such as emphysema and lung cancer, which have a predilection for the upper lobes of the lungs, may be due to regional variation of iron. In one study, BAL was taken from the upper and lower lobes of the lungs of smokers and nonsmokers. Fluid from the upper lobes of those who smoked had significantly higher concentrations of extracellular ferritin-bound iron and less transferrin, which may contribute to the pathogenesis of emphysema and lung cancer via oxidative stress [25]. Another study demonstrated that excess iron in the lung influenced the production of human alveolar macrophage-derived IL1beta, and this also showed regional variation [26], giving further support to the link between iron and inflammation, and clinical relevance to lung conditions that favour the upper lobes.

Maternal smokers have been shown to have a higher ferritin level in their placental cord blood than nonsmoking women, however there was a negative correlation between maternal smoking and infants' ferritin and total body iron [27].

Iron in the lung has been shown to increase with age, and again with smoking, although this effect is separate from senescence [28]. This increase in iron could account for the increased risk of lung injury seen with age [29]. Areas of emphysema in comparison to normal lung tissue have shown greater uptake of the polyclonal antibody for ferritin, and the increase in staining was not limited to alveolar macrophages but was seen throughout the epithelium [28]. This suggests that quick responses to iron are seen throughout the lung; with cells 


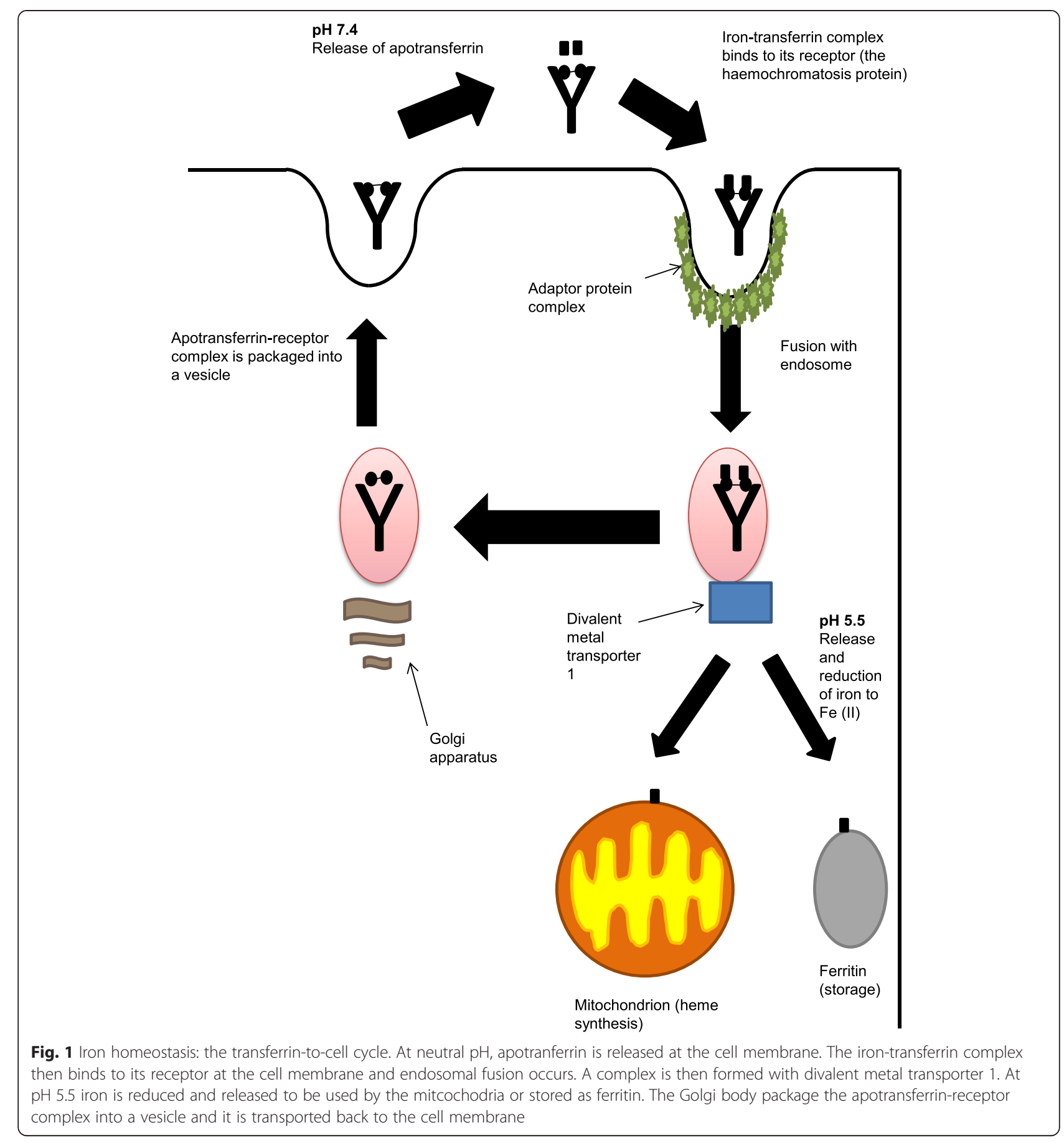

trying to limit oxidative damage by storing iron as ferritin.

\section{Chronic Obstructive Pulmonary Disease (COPD)}

IREB2 has been implicated as a COPD susceptibility gene in a case-control study [30]. Expression of IRP2 was higher in the lung tissue samples of those with COPD, and there was a trend for association for five IREB2 single-nucleotide polymorphisms (SNPs) with upper lobe emphysema [30].
Table 1 demonstrates combined $p$ values of the seven SNPs investigated in this study. Three of the SNPs investigated in this study were replicated in a later study [31]. The role of IREB2 and iron homeostasis was felt to be independent of the effect on lung function as there was no association between $\mathrm{FEV}_{1}$ and these SNPs [31]. Another paper showed that after adjusting for CHRNA3 and CHRNA5 (genes that are in strong LD with IREB2 and also known to be associated with $C O P D)$ this association was no longer significant 
Table 1 IREB2 single nucleotide polymorphisms and their association with chronic obstructive pulmonary disease

\begin{tabular}{llll}
\hline SNP & Risk allele & Minor allele & $\begin{array}{l}\text { Combined } p \text { using } \\
\text { Fisher's exact method }\end{array}$ \\
\hline rs2568494 & A & A & $1.64 \times 10^{-7}$ \\
rs2656069 & T & C & $1.03 \times 10^{-5}$ \\
rs1964678 & G & A & $5.94 \times 10^{-4}$ \\
rs12593229 & G & T & $9.21 \times 10^{-4}$ \\
rs10851906 & A & G & $1.65 \times 10^{-5}$ \\
rs965604 & A & G & $5.42 \times 10^{-4}$ \\
rs13180 & T & C & $6.42 \times 10^{-4}$ \\
\hline
\end{tabular}

[5]. Tight LD on this area of chromosome 15 complicates isolation of causal genes for COPD. The possibility that there are multiple functional genes in this locus controlling for different aspects of COPD is a valid one; CHRNA3 and CHRNA5 have been shown to be significantly associated with pack/years smoking and emphysema in COPD patients, whereas the most significant association for $\mathrm{FEV}_{1}$ was in an intron of IREB2 [32]. Further support for this is shown in a paper that demonstrates the effect of IREB2 on COPD is independent from smoking [33]. Long-range control of gene expression is another concept which should be considered, with greater than $85 \%$ of variants being associated with disease traits outside the coding region of annotated genes [34].

Alpha-1 antitrypsin deficiency (AATD) is a genetic disorder that may manifest with symptoms of COPD [35]. Severe AATD accounts for $0.63 \%$ of usual COPD [36]. In UK National Registry of AATD, IREB2 SNP rs2568494 was shown to be significantly associated with emphysema, and this effect appeared to be more prominent in males [37]. This cohort of patients also showed significant SNPby-smoking interactions, contrasting the research done in usual COPD [32]. Severity of AATD patients has been shown to correlate with iron, with patients with ZZ phenotype having significantly more ferritin and nonheme iron than those with MM phenotype [38].

Neutrophil elastase and oxidative stress is increased in the typical AATD lung. When neutrophil elastase levels are raised, levels of iron in the airways also increase when bronchoalveolar fluid is examined, but ferritin is degraded: this could be to increase the overall extracellular iron pool for cellular uptake [39].

\section{Lung cancer}

As with COPD, promising candidate genes such as CHRNA3 and CHRNA5 have been discovered in association with lung cancer [40], and as discussed in the section on COPD, these genes are in strong linkage disequilibrium with IREB2. As well as being identified in relation to lung cancer, these genes are also relevant to nicotine addiction [41-43]. It is interesting that both COPD and lung cancer are pathologies that are strongly linked to cigarette smoking, dependence on which could be linked to the same SNPs. The same genetic and environmental risk factors are shared for these diseases, meaning presence of these SNPs could confer increased susceptibility for all three things.

IRP2 has pro-oncogenic activity in human lung cancer cells, and this is variable depending on a specific 73 amino acid insert [44]. This pro-oncogenic activity is not able to proceed without IRP2: a causal relationship has been established by turning off the expression of IREB2 [44]. Depleting cancer cells of iron has been hypothesised as a potential therapy. Promising new research is emerging on the use of iron-chelating agents to treat lung cancer [45].

\section{Susceptibility to lung infections}

During times of infection, iron homeostasis adjusts so that cytokines scavenge iron from tissues and sequester it within macrophages. Microbes require iron to proliferate, and so the purpose of this is partly to deny invading organisms the iron they need; and partly to protect the host from the toxic effects of $\mathrm{Fe}^{2+}$ and the subsequent formation of superoxide radicals via the Fenton reaction that may be released during inflammation [10]. Microbes can produce small compounds called siderophores, which scavenge iron from the host by forming complexes which are then taken up by active transport [46]. In response, the host tries to make less iron available for the microbe, which is a state known as "the anaemia of inflammation" [4]. The iron status of the host is very important in determining risk of pulmonary infection. For example, correction of iron deficiency led to activation of previously suppressed pre-existing infections including malaria, brucellosis and tuberculosis, in a group of Somali nomads [47]. As iron repletion advanced, infectious activity reached a peak, showing that iron repletion can allow infectious diseases to become more clinically overt [47].

Mycobacterium tuberculosis employs the siderophore system to acquire iron [48]. The link between iron and tuberculosis virulence is further confirmed by studies into dietary iron. By increasing dietary intake of iron the host macrophages appear to be overloaded by iron and unable to suppress the spread of pulmonary tuberculosis [49]. In vitro work has shown that by deleting the gene that codes for siderophore production in Myocbacterium tuberculosis, it is unable to grow and replicate within macrophages [48]. This suggests that siderophore biosynthesis may be a promising candidate for new antibiotics to target with regards to tuberculosis treatment. Indeed, a siderophore analog has been coupled with the antimalarial artemisinin, and has successfully been shown to retain antimalarial properties as well as combat tuberculosis in vitro [50]. More recently a further siderophore-independent pathway has been established, where Mycobacterium tuberculosis is able to use free heme and heme from haemoglobin as an 
iron source [51], providing a new line of investigation for future therapies to target.

Patients with severe pneumonia have been shown to have elevated levels of sideromacrophages in their BAL fluid [52], reflecting higher levels of iron in the airways of these patients. Animal models have also shown that iron acquisition is critically important in the pathogenesis of Staphylococcus aureus pneumonia [53] and Klebsiella pneumoniae pneumonia [54]. Host defences, such as production of the protein lipocalin 2, are able to bind the main siderophores produced by Klebsiella pneumoniae and stop them from scavenging iron [54]. Streptococcus pneumoniae growth has been observed in media containing differing levels of iron and manganese. When the iron content was high iron homeostasis was disrupted and the bacteria were susceptible to oxidative stress [55]. However, manganese proved to protect the bacteria via its antioxidant effect and competed with iron for transport into the bacterium [55]. This work demonstrates the role of other transition metal ions with regards to pulmonary inflammation. The mechanisms by which lipocalin 2 protects the host, and manganese works to protect the bacteria, could be exploited with regards to treatment of pneumonia. To our knowledge, there is a lack of published work on therapies targeting iron in pneumonia.

Gram negative lung pathogens such as Haemophilus influenza have developed strategies to acquire iron by using iron-containing human proteins such as tranferrin, lactoferrin, haemoglobin and ferritin [56-58]. The bacterial receptors have evolved to compete with human receptors and transferring binds to bacterial receptors preferentially [59]. Gram positive species such as Streptococcus pneumoniae have also developed iron-acquistion strategies separate from siderophores. Hemophores are proteins that bacteria secrete to bind heme from the host [60]. As well as indirectly using heme chelation, Streptococcus, like the Gram negative bacteria, can directly acquire iron by hijacking iron-containing human proteins [60].

Another pulmonary pathology that demonstrates that iron is key for airway bacterial growth is cystic fibrosis (CF). Elevated levels of iron have been found in the respiratory tracts of these patients, implying disrupted iron homeostasis [61]. Pseudomonas aeruginosa is the microorganism responsible for the majority of CF infectious exacerbations. Around $6 \%$ of the genes in Pseudomonas aeruginosa are iron-responsive [62], and they take some responsibility for production of the siderophores that allow microbes to scavenge iron from the host. Pseudomonas aeruginosa exists in biofilms, which make it difficult for antibiotics to eradicate this microbe [61]. Iron also plays a role in strengthening the structure of these biofilms [63], enabling the bacteria to have an extra defence against the host.
Pseudomonas aeruginosa may also acquire iron from the host via siderophore-independent pathways. For example, proteases employed by microbes have been shown to cleave iron from host proteins in order to utilise the iron for their own purposes [64]. Pulmonary haemorrhage is a common complication of CF exacerbations. During these episodes heme-bound iron can be taken up via two separate pathways, but no formal data exists on these as yet [61].

Novel adjuvants to anti-pseudomonal antibiotics are under investigation, namely iron chelators such as gallium and desferrioxamine [65]. In vitro work has shown that a formulation containing gentamicin and gallium is more effective than gentamicin alone against Pseudomonas aeruginosa grown within a biofilm [66]. Desferrioxamine in combination with tobramycin was efficacious at disrupting established biofilms, as well as preventing the formation of new biofilms on epithelial cells from CF patients [67].

\section{Acute Respiratory Distress Syndrome (ARDS)}

ARDS is a severe form of inflammatory lung disease. Ferritin levels have been shown to be a marker of both developing ARDS and multiple organ failure in trauma patients [68]. The authors of this study discuss that ferritin could be raised as a result of being induced by proinflammatory cytokines, however the role of ferritin as an acute phase reactant is not discussed as a confounder in the paper. Ferritin was not associated with other markers of clinical injury in this study, for example, $\mathrm{PaO}_{2} / \mathrm{FiO}_{2}$ ratio, days requiring ventilation, and mortality [68]. Samples of BAL fluid from those with ARDS have significantly higher levels of iron than samples from healthy volunteers [69]. This lends support to the hypothesis that disrupted iron homeostasis causes increased oxidative stress and tissue damage in people with ARDS.

Transfusion-related acute lung injury (TRALI) is a form of ARDS associated with the process of blood transfusion. Pathogenesis of TRALI is unclear, but it has been suggested that iron in the blood components being transfused elevate iron levels in the recipient, and this causes damage to the cells by disruption of iron homeostasis [70]. At present, there are no clinical or in vitro trials aimed at stopping this.

\section{Recent advancements}

Over the last two years there has been increased interest in the role of iron in pulmonary pathology. The majority of research has been looking into how iron oxide particles can be used as novel nanoprobes to diagnose and treat lung disease. Superparamagnetic iron oxide nanoparticles have successfully been administered into lungs and detected on magnetic resonance imaging [71]. In mice, these probes have been used to visualise areas of angiogenesis in lung cancer [72]. In vitro drug delivery in lung 
cancer has been successfully developed by using these nanoparticles coated in gelatin [73].

\section{Conclusion}

The role of iron in pulmonary pathology has been well established, both from an environmental viewpoint as well as in terms of genetic susceptibility. Disruption of cellular iron homeostasis appears to have an adverse effect on the lung. Further work on this metal could look at the role of iron in prevention and treatment of pulmonary pathology, either by dietary deficiency, venesection or chelator therapy.

\begin{abstract}
Abbreviations
AATD: Alpha-1 antitrypsin deficiency; ARDS: Acute respiratory distress syndrome; BAL: Bronchoalveolar lavage; CF: Cystic fibrosis; CHRNA: Cholinergic receptor, neuronal nicotinic, alpha; COPD: Chronic obstructive pulmonary disease; $\mathrm{FEV}_{1}$ : Forced expiratory volume in 1 second; IRE: Iron responsive element; IREB: Iron responsive element binding protein; IRP: Iron regulatory protein; LD: Linkage disequilibrium; mRNA: messenger ribonucleic acid; SNP: Single nucleotide polymorphism.
\end{abstract}

\section{Competing interests}

\section{HK has no competing interests.}

AMT has non-financial interests in relation to this manuscript: a grant outside the submitted work from the Alpha 1 Foundation which pertains to the function of the gene IREB2 in alpha 1 antitrypsin deficiency. AMT is also in receipt of fees for educational talks or travel to conferences from AZ, GSK, Boehringer, Chiesi and Novartis within the last 5 years.

\section{Authors' contributions}

HK wrote the first draft of the manuscript. AMT contributed to the writing of the manuscript. Both authors reviewed and approved the final manuscript.

\section{Authors' information}

HK (MBBCh, BSc) currently works in an NIHR-funded post as an Academic Clinical Fellow in Respiratory Medicine at the University of Birmingham and Queen Elizabeth Hospital Birmingham.

AMT (PhD, MBChB) currently works as a Senior Lecturer at the University of Birmingham and as an Honorary Consultant Respiratory Physician at the Heart of England NHS Foundation Trust.

\section{Acknowledgements}

AMT has non-financial interests in relation to this manuscript: a grant outside the submitted work from the Alpha 1 Foundation which pertains to the function of the gene IREB2 in alpha 1 antitrypsin deficiency. AMT is also in receipt of fees for educational talks or travel to conferences from $A Z$, GSK, Boehringer, Chiesi and Novartis within the last 5 years.

The above-mentioned sponsors did not play a role in the conception, writing or approval of the manuscript; or the decision to submit the manuscript for publication. Publication of this article was funded by the Open Access Publications at University of Birmingham.

\section{Author details}

${ }^{1}$ School of Clinical and Experimental Medicine, University of Birmingham, Birmingham B15 2TT, UK. ${ }^{2}$ Centre for Translational Inflammation Research, Queen Elizabeth Hospital, Mindelsohn Way, Edgbaston, Birmingham B15 2GW, UK. ${ }^{3}$ Heartlands Hospital, Bordesley Green East, Birmingham B9 5SS, UK.

Received: 30 April 2015 Accepted: 18 September 2015 Published online: 01 December 2015

\section{References}

1. Hubbard R. The burden of lung disease. Thorax. 2006;61(7):557-8.

2. Morgan JW, Anders E. Chemical-composition of earth, venus, and mercury. Proc Natl Acad Sci U S A. 1980;77(12):6973-7.
3. Ghio AJ, Hilborn ED, Stonehuerner JG, Dailey LA, Carter JD, Richards JH, et al. Particulate matter in cigarette smoke alters iron homeostasis to produce a biological effect. Am J Respir Crit Care Med. 2008;178(11):1130-8.

4. Ghio AJ. Disruption of iron homeostasis and lung disease. Biochim Biophys Acta. 2009;1790(7):731-9.

5. Hardin M, Zielinski J, Wan ES, Hersh CP, Castaldi PJ, Scwinder E, et al CHRNA3/5, IREB2, and ADCY2 are associated with severe chronic obstructive pulmonary disease in Poland. Am J Respir Cell Mol Biol. 2012;47(2):203-8.

6. Walling C, Partch RE, Weil T. Kinetics of the decomposition of hydrogen peroxide catalyzed by ferric ethylenediaminetetraacetate complex. Proc Natl Acad Sci U S A. 1975;72:140-42.

7. Park CH, Bacon BR, Brittenham GM, Tavill AS. Pathology of dietary carbonyl iron overload in rats. Lab Invest. 1987;57:555-63.

8. Ganz T. Hepcidin in iron metabolism. Curr Opin Hematol. 2004;11(4):251-4.

9. Hentze MW, Muckenthaler MU, Andrews NC. Balancing acts: molecular control of mammalian iron metabolism. Cell. 2004;117(3):285-97.

10. Ganz T, Nemeth E. Iron homeostasis in host defence and inflammation. Nat Rev Immunol. 2015;15(8):500-10.

11. Aisen P. Transferrin, the transferrin receptor, and the uptake of iron by cells. Met lons Biol Syst. 1998;35:585-631.

12. Aisen P. Transferrin receptor 1. Int J Biochem Cell Biol. 2004;36(11):2137-43.

13. Silva B, Faustino P. An overview of molecular basis of iron metabolism regulation and the associated pathologies. Biochim Biophys Acta. 2015;1852(7):1347-59.

14. Rouault T, Klausner R. Regulation of iron metabolism in eukaryotes. Curr Top Cell Regul. 1997;35:1-19.

15. Rouault TA. The role of iron regulatory proteins in mammalian iron homeostasis and disease. Nat Chem Biol. 2006;2(8):406-14.

16. LaVaute T, Smith S, Cooperman S, Iwai K, Land W, Meyron-Holtz E, et al. Targeted deletion of the gene encoding iron regulatory protein-2 causes misregulation of iron metabolism and neurodegenerative disease in mice. Nat Genet. 2001;27(2):209-14

17. Galy B, Ferring D, Minana B, Bel O, Janser HG, Muckenthaler M, et al. Altered body iron distribution and microcytosis in mice deficient in iron regulatory protein 2 (IRP2). Blood. 2005;106(7):2580-9.

18. Meyron-Holtz EG, Ghosh MC, Iwai K, LaVaute T, Brazzolotto X, Berger UV, et al. Genetic ablations of iron regulatory proteins 1 and 2 reveal why iron regulatory protein 2 dominates iron homeostasis. EMBO J. 2004;23(2):38695.

19. Pantopoulos K, Porwal SK, Tartakoff A, Devireddy L. Mechanisms of mammalian iron homeostasis. Biochemistry. 2012;51(29):5705-24.

20. Guo B, Phillips JD, Yu Y, Leibold EA. Iron regulates the intracellular degradation of iron regulatory protein 2 by the proteasome. J Biol Chem. 1995;270(37):21645-51.

21. Chepelev NL, Willmore WG. Regulation of iron pathways in response to hypoxia. Free Radic Biol Med. 2011;50(6):645-66.

22. Hanson ES, Foot LM, Leibold EA. Hypoxia post-translationally activates iron-regulatory protein 2. J Biol Chem. 1999;274(8):5047-52.

23. Kirschner RE, Fantini GA. Role of iron and oxygen-derived free radicals in ischemia-reperfusion injury. J Am Coll Surg. 1994;179(1):103-17.

24. Guo RF, Ward PA. Mediators and regulation of neutrophil accumulation in inflammatory responses in lung: Insights from the lgG immune complex model. Free Radical Biol Med. 2002;33(3):303-10.

25. Nelson ME, O'Brien-Ladner AR, Wesselius L. Regional variation in iron and ironbinding proteins within the lungs of smokers. Am J Respir Crit Care Med. 1996;153(4 Pt 1):1353-8.

26. O'Brien-Ladner AR, Nelson SR, Murphy WJ, Blumer BM, Wesselius LJ. Iron is a regulatory component of human IL-1beta production. Support for regional variability in the lung. Am J Respir Cell Mol Biol. 2000;23(1):112-9.

27. Pateva IB, Kerling EH, Reddy M, Chen D, Carlson SE, Tancabelic J. Effect of maternal cigarette smoking on newborn iron stores. Clin Res Trials. 2015;1(1):4-7.

28. Ghio AJ, Pritchard RJ, Dittrich KL, Samet JM. Non-heme (Fe3+) in the lung increases with age in both humans and rats. J Lab Clin Med. 1997;129(1):53-61.

29. Rubenfeld GD, Caldwell E, Peabody E, Weaver J, Martin DP, Neff M, et al. Incidence and outcomes of acute lung injury. N Engl J Med. 2005;353(16):1685-93.

30. DeMeo DL, Mariani T, Bhattacharya S, Srisuma S, lange C, Litonjua A, et al. Integration of genomic and genetic approaches implicates IREB2 as a COPD susceptibility gene. Am J Hum Genet. 2009;85(4):493-502. 
31. Chappell SL, Daly L, Lotya J, Alsaegh A, Guetta-Baranes T, Roca J, et al. The role of IREB2 and transforming growth factor beta-1 genetic variants in COPD: a replication case-control study. BMC Med Genet. 2011;12:24

32. Pillai SG, Kong X, Edwards LD, Cho MH, Anderson WH, Coxson HO, et al. Loci identified by genome-wide association studies influence different disease-related phenotypes in chronic obstructive pulmonary disease. Am J Respir Crit Care Med. 2010;182(12):1498-505.

33. Zhou H, Yang J, Li D, Xiao J, Wang B, Wang L, et al. Association of IREB2 and CHRNA3/5 polymorphisms with COPD and COPD-related phenotypes in a Chinese Han population. J Hum Genet. 2012;57(11):738-46.

34. Pastinen T. Genome-wide allele-specific analysis: insights into regulatory variation. Nat Rev Genet. 2010;11(8):533-8.

35. Needham M, Stockley RA. Alpha 1-antitrypsin deficiency. 3: Clinical manifestations and natural history. Thorax. 2004;59(5):441-5.

36. Rahaghi FF, Sandhaus RA, Brantly ML, Rouhani F, Campos MA, Strange C, et al. The prevalence of alpha-1 antitrypsin deficiency among patients found to have airflow obstruction. COPD. 2012;9(4):352-8.

37. Kim WJ, Wood AM, Barker AF, Brantly ML, Campbell EJ, Eden E, et al. Association of IREB2 and CHRNA3 polymorphisms with airflow obstruction in severe alpha-1 antitrypsin deficiency. Respir Res. 2012;13:16.

38. Ghio AJ, Soukup JM, Richards JH, Fischer BM, Voynow JA, Schmechel DE. Deficiency of alpha-1-antitrypsin influences systemic iron homeostasis. Int J Chron Obstruct Pulmon Dis. 2013;8:45-51.

39. Fischer BM, Domowicz DA, Zheng S, Carter JL, McElvaney NG, Taggart C, et al. Neutrophil elastase increases airway epithelial nonheme iron levels. Clin Transl Sci. 2009;2(5):333-9.

40. Amos Cl, Wu X, Broderick P, Gorlov IP, Gu J, Eisen T, et al. Genome-wide association scan of tag SNPs identifies a susceptibility locus for lung cancer at 15q25.1. Nat Genet. 2008;40(5):616-22.

41. Spitz MR, Amos Cl, Dong Q, Lin J, Wu X. The CHRNA5-A3 region on chromosome 15q24-25.1 is a risk factor both for nicotine dependence and for lung cancer. J Natl Cancer Inst. 2008;100(21):1552-6.

42. Hung RJ, McKay JD, Gaborieau V, Boffetta P, Hashibe M, Zaridze D, et al. A susceptibility locus for lung cancer maps to nicotinic acetylcholine receptor subunit genes on 15q25. Nature. 2008;452(7187):633-7.

43. Thorgeirsson TE, Geller F, Sulem P, Rafnar T, Wiste A, Magnusson KP, et al. A variant associated with nicotine dependence, lung cancer and peripheral arterial disease. Nature. 2008;452(7187):638-42.

44. Maffettone C, Chen G, Drozdov I, Ouzounis C, Pantapoulos K. Tumorigenic properties of iron regulatory protein 2 (IRP2) mediated by its specific 73amino acids insert. PLoS One. 2010;5(4):e10163.

45. Lui GY, Obeidy P, Ford SJ, Tselepis C, Sharp DM, Jansson PJ, et al. The iron chelator, deferasirox, as a novel strategy for cancer treatment: oral activity against human lung tumor xenografts and molecular mechanism of action. Mol Pharmacol. 2013;83(1):179-90.

46. Weinberg ED. Iron and susceptibility to infectious disease. Science. 1974;184(4140):952-6.

47. Murray MJ, Murray AB, Murray MB, Murray CJ. The adverse effect of iron repletion on the course of certain infections. Br Med J. 1978;2(6145):1113-5.

48. De Voss JJ, Rutter K, Schroeder BG, Su H, Zhu Y, Barry CE 3rd. The salicylatederived mycobactin siderophores of Mycobacterium tuberculosis are essential for growth in macrophages. Proc Natl Acad Sci U S A. 2000;97(3):1252-7.

49. Gangaidzo IT, Moyo VM, Myundura E, Aggrey G, Murphree NL, Khumalo H, et al. Association of pulmonary tuberculosis with increased dietary iron. J Infect Dis. 2001;184(7):936-9.

50. Miller MJ, Walz AJ, Zhu H, Wu C, Moraski G, Möllmann U, et al. Design, synthesis, and study of a mycobactin-artemisinin conjugate that has selective and potent activity against tuberculosis and malaria. J Am Chem Soc. 2011;133(7):2076-9.

51. Tullius MV, Harmston CA, Owens CP, Chim N, Morse RP, McMath LM, et al. Discovery and characterization of a unique mycobacterial heme acquisition system. Proc Natl Acad Sci U S A. 2011;108(12):5051-6.

52. Grigoriu B, Jacobs F, Beuzen F, El Khoury R, Axler O, Brivet FG, et al. Bronchoalveolar lavage cytological alveolar damage in patients with severe pneumonia. Crit Care. 2006;10(1):R2.

53. Mason WJ, Skaar EP. Assessing the contribution of heme-iron acquisition to Staphylococcus aureus pneumonia using computed tomography. PLoS One. 2009;4(8):e6668

54. Bachman MA, Lenio S, Schmidt L, Oyler JE, Weiser JN. Interaction of lipocalin 2, transferrin, and siderophores determines the replicative niche of
Klebsiella pneumoniae during pneumonia. MBio, 2012. 3(6). doi:10.1128/ mBio.00224-11.

55. Ong CL, Potter AJ, Trappetti C, Walker MJ, Jennings MP, Paton JC, et al. Interplay between manganese and iron in pneumococcal pathogenesis: role of the orphan response regulator RitR. Infect Immun. 2013;81(2):421-9.

56. Perkins-Balding D, Ratliff-Griffin M, Stojiljkovic I. Iron transport systems in Neisseria meningitides. Microbiol Mol Biol Rev. 2004;68:154-71.

57. Alacantara J, Yu RH, Schryvers $A B$. The region of human transferring involved in binding to bacterial transferring receptors is localized in the C-lobe. Mol Microbiol. 1993;8:1135-43.

58. Larson JA, Howie HL, So M. Neisseria meningitides accelerates ferritin degradation in host epithelial cells to yield an essential iron source. Mol Microbiol. 2004:53:807-20.

59. Barber MF, Elde NC. Escape from bacterial iron piracy through rapid evolution of transferring. Science. 2014;346:1362-66.

60. Ge R, Sun X. Iron acquisition and regulation systems in Streptococcus species. Metallomics. 2014;6(5):996-1003.

61. Reid DW, Anderson GJ, Lamont IL. Role of lung iron in determining the bacterial and host struggle in cystic fibrosis. Am J Physiol Lung Cell Mol Physiol. 2009;297(5):L795-802.

62. Vasil ML, Ochsner UA. The response of Pseudomonas aeruginosa to iron: genetics, biochemistry and virulence. Mol Microbiol. 1999;34(3):399-413.

63. Chen $X$, Stewart PS. Role of electrostatic interactions in cohesion of bacterial biofilms. Appl Microbiol Biotechnol. 2002;59(6):718-20.

64. Britigan BE, Hayek MB, Doebbeling BN, Fick RB Jnr. Transferrin and lactoferrin undergo proteolytic cleavage in the Pseudomonas aeruginosainfected lungs of patients with cystic fibrosis. Infect Immun. 1993;61(12):5049-55.

65. Hurley MN, Camara M, Smyth AR. Novel approaches to the treatment of Pseudomonas aeruginosa infections in cystic fibrosis. Eur Respir J. 2012;40(4):1014-23.

66. Halwani M, Yebio B, Suntres ZE, Alipour M, Azghani AO, Omri A. Coencapsulation of gallium with gentamicin in liposomes enhances antimicrobial activity of gentamicin against Pseudomonas aeruginosa. J Antimicrob Chemother. 2008;62(6):1291-7

67. Moreau-Marquis S, O'Toole GA, Stanton BA. Tobramycin and FDA-approved iron chelators eliminate Pseudomonas aeruginosa biofilms on cystic fibrosis cells. Am J Respir Cell Mol Biol. 2009;41(3):305-13.

68. Sharkey RA, Donnelly SC, Connelly KG, Robertso CE, Haslett C, Repine JE. Initial serum ferritin levels in patients with multiple trauma and the subsequent development of acute respiratory distress syndrome. Am J Respir Crit Care Med. 1999;159(5 Pt 1):1506-9.

69. Ghio AJ, Carter JD, Richards JH, Richer LD, Grissom CK, Elstad MR. Iron and iron-related proteins in the lower respiratory tract of patients with acute respiratory distress syndrome. Crit Care Med. 2003;31(2):395-400.

70. Jenkins ZA, Hagar W, Bowlus CL, Johansson HE, Harmatz P, Vichinsky EP, et al. Iron homeostasis during transfusional iron overload in beta-thalassemia and sickle cell disease: changes in iron regulatory protein, hepcidin, and ferritin expression. Pediatr Hematol Oncol. 2007;24(4):237-43.

71. Al Faraj A, Shaik AP, Shaik AS. Effect of surface coating on the biocompatability and in vivo MRI detection of iron oxide nanoparticles after intrapulmonary administration. Nanotoxicology. 2015;10:1-10.

72. Xue S, Zhang C, Yang Y, Zhang L, Cheng D, Zhang J, et al. 99mTc-Labeled iron oxide nanoparticles for dual-contrast (T1/T2) magnetic resonance and dual-modality imaging of tumor angiogenesis. J Biomed Nanotechnol. 2015;11(6):1027-37.

73. Hamarat Sanlier S, Yasa M, Cihnioglu AO, Abdulhayoglu M, Yilmaz H, Ak G. Development of gemcitabine-adsorbed magnetic gelatin nanoparticles for targeted drug delivery in lung cancer. Artif Cells Nanomed Biotechnol. 2015;23:1-7. 